\title{
Pedagogia da práxis: \\ pensar a educação com Adolfo Sáchez Vázquez
}

FERREIRA, Naura Syria Carapeto (Org.).

Adolfo Sánchez Vázquez: para pensar a educação.

Editora CRV: Curitiba, 2018.

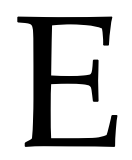

m tempos como os nossos de perseguição aos intelectuais e de ataques e desvalorização da filosofia, da ciência e da cultura de maneira geral, a leitura de uma obra dedicada ao pensamento de um filósofo revolucionário como foi Adolfo Sánchez Vázquez pode ser considerada uma atividade corajosa e de resistência. Ainda mais corajosa, exemplar e necessária é a atividade de pesquisadores(as), que, não obstante aos fatores limitantes provenientes das mais diversas ordens, se empenham em perquirir a vida, a obra, a práxis de pensadores que deixaram sua marca no mundo e valiosas contribuições para a compreensão e a transformação da realidade no horizonte da humanização.

Prefaciada por Décio Junkes e contando com um anteâmbulo da organizadora, Naura Syria Carapeto Ferreira, que abre passagem a fim de que os demais autores apresentem os resultados de seus estudos, essa coletânea de textos se oferece como uma contribuição valiosa aos pesquisadores da área de educação, principalmente para aqueles que se dedicam ao estudo do fenômeno educativo balizados pelo aporte teórico do materialismo histórico.

No capítulo intitulado: Adolfo Sánchez Vázquez: fidelidade e congruência do filósofo da práxis, a organizadora, Naura Syria Carapeto Ferreira, que teve a oportunidade de entrevistar o filósofo e eminente intelectual, apresenta uma síntese a vida e o legado do filósofo da práxis, cuja trajetória é marcada pelo compromisso com o socialismo e os princípios da fraternidade, solidariedade e respeito ao outro. Ressalta-se na exposição do capítulo a descrição da experiência poética e política militar, que serviram de ponto de partida para o desenvolvimento do pensamento filosófico de Sánchez Vázquez. Além de filosofar, Vázquez soube poetizar os momentos que viveu. Sócrates, Marx, Gramsci e Antônio Machado foram pensadores que o marcaram intelectualmente e influenciaram o desenvolvimento de seu humanismo. A vida e a obra de Vázquez são apresentadas como fundamentos para a promoção de uma educação humanizada e humanizadora.

Os professores Geraldo Balduino Horn e Ademir Aparecido Pinhelli Mendes, no capítulo: A práxis como atitude ética e revolucionária em Adolfo Sánchez Vázquez analisam os pressupostos da concepção filosófica de atitude ética do autor. Os autores destacam que 
Vázquez, assim como outros pensadores marxistas, também assevera que a contribuição significativa da filosofia marxista se deu a partir da crítica: 1) à economia inglesa (David Ricardo e Adam Smith), 2) à utopia política francesa, e, 3) ao idealismo hegeliano, cuja dialética estava mistificada e invertida. Nesse sentido, o método marxista com o qual trabalha Vázquez questiona ao mesmo tempo a perspectiva idealista e o materialismo mecanicista, sendo a práxis revolucionária, que fundamentou a ética vazquezina, concebida como a indissolubilidade entre a teoria e a prática, ou seja, entre pensamento e ação. Assim, a contribuição da filosofia para a formação humana ocorrerá na medida em que se concretizar como práxis pedagógica libertadora.

Como é possível notar na exposição dos autores ao longo do texto, e mais especificamente na contribuição de Fausto dos Santos Amaral Filho, Adolfo Sánchez Vázquez soube com maestria adentrar na tradição filosófica marxista e marxiana, sem fazer disso um fator de limitação ou muleta epistemológica que conduziria a um repouso no sono dogmático. Pelo contrário, Sánchez Vázquez, é um filósofo imerso na tradição marxista, sem considerá-la um cabedal de verdades absolutas, cujo pensamento provoca, desperta, incomoda e incentiva o agir revolucionário em prol do humano e da concretização do mundo humanizado. Na perspectiva vazquezina a arte permanece viva e possui uma vocação revolucionária que conflui para a instauração de uma sociedade mais justa, uma vez que conclama à participação.

Em um texto conciso, mas de possibilidades analíticas, Breves notas sobre Adolfo Sánchez Vázquez leitor e tradutor de Karel Kosik, Pedro Leão da Costa Neto enfatiza o interesse dado pelo filósofo hispano-mexicano à obra de Karel Kosik, bem como de sua importância para a recuperação da vitalidade de Marxismo que, nessa perspectiva, precisaria revestir a forma de uma filosofia da ação. A teoria marxista não pode ser reduzida a uma teoria do conhecimento, pois ciência marxista e ideologia revolucionária precisam caminhar juntas e entrelaçadas para não incorrer no risco de cair em um novo cientificismo estéril. Por fim, é possível dizer que a leitura vazquezina de Kosik possibilita ressaltar o caráter humanista e fenomenológico do marxismo, sem perder de vista sua centralidade na práxis revolucionária.

Debruçando-se sobre a análise da Cultura docente: tolerância e liberdade em uma leitura de Adolfo S. Vázquez, Roberta Ravagglio Gagno ressalta a utopia socialista como um dever ser para os que almejam construir um novo mundo. Desenvolver uma cultura docente crítica é uma necessidade no mundo atual, marcado pela competição, intolerância e crescente desumanização. A partir da ótica vazquezina, a tolerância não é vista como valor absoluto, mas como valor integrante e importante na construção da cultura docente que busca a promoção de uma sociedade na qual a convivência seja pautada na ética, no respeito ao outro e na justiça social.

A professora Josélia Schwanka Salomé no texto Educação, estética e a formação dos sentidos humanos: escritos a partir de Adolfo Sánchez Vázquez discute a arte na educação e a 
formação dos sentidos humanos com base nas obras Convite à Estética e As Ideias Estéticas em Marx. Destaca-se no texto a reflexão sobre a problemática que poderia ser caracterizada como "ditadura do utilitarismo", ou seja, a redução da arte e mesmo do ideal de educação aos interesses do mercado e do consumismo, que trazem por consequência a diminuição ou mesmo a perda da liberdade humana e do seu potencial criativo e transformador. Vale citar aqui, conforme faz a autora, as palavras de Paulo Leminski: "As pessoas sem imaginação estão sempre querendo que a arte sirva para alguma coisa, Servir, Prestar. O serviço militar. Dar lucro. Não enxergam que a arte (a poesia é arte) é a única chance que o homem tem de vivenciar a experiência de um mundo da liberdade, além da necessidade". De acordo com Sánchez Vázquez, a própria natureza da arte torna problemática suas relações com a sociedade, pois toda grande obra de arte carrega consigo a busca pela universalidade, ou dito com outras palavras, a grande arte é uma afirmação universal do humano. Nesse sentido, a educação estética é primordial pois conflui com o desenvolvimento do potencial criativo e transformador do ser humano enquanto ser dotado de liberdade.

No capítulo Práxis e violência: rumo à possibilidade de sua superação, a organizadora, não obstante à presença de importantes estudos sobre a natureza da violência que afloram ao longo da história, destaca a contribuição de Adolfo Sánchez Vázquez para compreensão e superação desse fenômeno. A violência foi um dos temas centrais aos quais se dedicou o filósofo hispano-mexicano, que já em sua tese de doutorado apresentou um denso capítulo ressaltando a exclusividade da violência enquanto propriedade humana. As contribuições de Vázquez no campo da filosofia da práxis e da violência, reforçam a importância da educação e suas possibilidades transformadoras. O ser humano precisa inventar constantemente novas soluções e não se contenta em repeti-las, pois, as novas necessidades e exigências da vida, criadas inclusive pelo próprio homem, invalidam as soluções anteriores e o impelem a criar o novo e buscar novos caminhos de superação. Assim, a práxis entendida como a indissociabilidade entre teoria e prática apresenta-se como possibilidade de compreensão do real e de sua transformação, com vistas à superação da violência e à concretização da gestão democrática de uma concepção de educação humanizada e humanizadora que colabore para o cumprimento do compromisso inalienável de reconstituição das relações sociais de reciprocidade, tolerância, liberdade, igualdade e fraternidade.

Maria Iolanda Fontana, no capítulo intitulado A contribuição de Adolfo Sánchez Vázquez à produção do conhecimento em educação apresenta uma cartografia das pesquisas no campo educacional no Brasil que adotam como referencial teórico-metodológico o pensamento de Vázquez, mais especificamente, a filosofia da práxis, "entendida como a expressão da teoria de Marx, na produção do conhecimento em educação e no trabalho do professor". O resultado desse esforço em inventariar teses, dissertações e artigos na área de educação no Brasil que assumem o pensamento vazquezino como referencial 
teórico-metodológico revela que, apesar de sua relevância, as obras do filósofo hispano-mexicano são pouco estudadas no Brasil. Filosofia da práxis é o livro mais citado na perspectiva de defender e elevar a consciência filosófica dos profissionais da educação com vistas à transformação das relações sociais capitalistas injustas e opressoras.

Em Práxis revolucionária dos professores em EAD na concepção de Adolfo Sánchez Vázquez como garantia dos direitos humanos, Márcia Regina Mocelin e Dinamara Pereira Machado reúnem um conjunto de concepções, agrupadas em três momentos, que vão desde revisitar as noções de práxis em utopia em Vázquez, passando pela práxis dos professores que atuam na educação a distância $(\mathrm{EaD})$, até a busca de uma harmonia na qual o ser humano ocupe uma posição de centralidade. A partir da obra Filosofia da Práxis, as autoras apresentam um quadro sintético acerca da compreensão de práxis, ressaltando as seguintes categorias: produtiva, política, filosófica e revolucionária. Também realizam uma revisão de diferentes perfis no decorrer do capítulo para explicitar que novas áreas de atuação se abrem ao professor na EAD, ainda que a centralidade esteja na docência. Para as autoras, as utopias projetadas por um professor em particular ou por um grupo de docentes podem provocar mudanças sociais.

No décimo capítulo da coletânea, Maria Iolanda Fontana, em A pesquisa na dimensão da práxis no trabalho docente: aportes teóricos de Adolfo Sànchez Vázquez, discute a concepção de pesquisa na dimensão da práxis no trabalho docente, tendo como referência a filosofia da práxis. Para a autora, a pesquisa no horizonte da práxis tem um papel revolucionário e, quando apropriada pelos profissionais da educação, produz o saber contra hegemônico, que precisa orientar o trabalho pedagógico na promoção de uma educação que almeja a formação omnilateral. Não obstante os diferentes entendimentos quanto ao momento no qual o marxismo se firmou enquanto teoria esclarecedora da práxis e fundamento da prática revolucionária, a autora salienta que, segundo Vázquez, este encontro entre pensamento e ação se deu a partir do Manifesto do Partido Comunista. A interpretação de Gramsci reitera a centralidade da práxis no marxismo e sua explicitação enquanto filosofia revolucionária. A filosofia marxista revela todo seu potencial transformador quando assimilada pela consciência das massas, ou seja, quando passa do plano teórico para o prático, cabendo aos intelectuais a tarefa de oferecer a elas (às massas) solidez cultural e organicidade. Nessa perspectiva, para os profissionais da educação, o desenvolvimento da consciência filosófico-científica, na dimensão da práxis, possibilita ao professor não apenas a interpretação, mas a transformação da realidade, superando o sentido utilitário, instrumental e imediato da prática humana.

Por fim, Sarita Aparecida de Oliveira Fortunato, em A práxis intencional, sob a concepção de Vázquez, na vida das crianças trabalhadoras: educação e direitos da infância, analisa, a partir das proposições vazquezinas, as implicações da inserção precoce da criança no mundo do trabalho e as políticas públicas para a erradicação do trabalho infantil. Comenta-se a contribuição de Vázquez em sua obra Filosofia da Práxis ao distinguir a atividade 
cotidiana da não cotidiana. Enquanto a primeira diz respeito à reprodução da vida, a segunda impacta sobre toda a humanidade no que diz respeito à ética, política, ciência, estética e arte. Nesta perspectiva, a práxis, na ótica vazquezina, é apresentada como categoria central da filosofia marxista enquanto atividade da consciência e material do homem social, com vistas à interpretação do mundo e sua transformação. A partir dessa compreensão de práxis, analisa-se o direcionamento das atuais políticas para a erradicação do trabalho infanto-juvenil, bem como as relações entre escola pública e conselhos tutelares no Paraná referentes às crianças trabalhadoras sob o ponto de partida da práxis na vida social. Conclui-se as análises com um levantamento de proposições relacionadas às políticas públicas, que se apresentam como desafios a serem superados para a erradicação do trabalho infantil no Brasil.

A diversidade de temas e perspectivas de análise apresentados ao longo desta obra reafirmam a originalidade, profundidade e fecundidade do pensamento vazquezino para analisar os desafios éticos, políticos, econômicos, sociais, ambientais de nosso tempo, entre outros, que estão relacionados com a educação, e que, ao longo desta coletânea, foi pensada e analisada a partir da centralidade da categoria práxis no pensamento de Adolfo Sánchez Vázquez.

Recebido em: 03/09/2019 e Aprovado em: 25/09/2019

\section{Sobre o autor:}

\section{LUÍS FERNANDO LOPES}

Doutor e mestre em Educação pela Universidade Tuiuti do Paraná. Atualmente atua como professor no Centro Universitário UNINTER, nos cursos de Filosofia e Licenciatura em Artes Visuais (EAD). E-mail:<luis.l@uninter.com>. 